\title{
Nanofibrillated Cellulose Rheology: Effects of Morphology, Ethanol/Acetone Addition, and High $\mathrm{NaCl}$ Concentration
}

\author{
Vera L. D. Costa, Ana P. Costa, and Rogério M. S. Simões *
}

The effects of ethanol or acetone addition (2.5\% to $40 \% \mathrm{w} / \mathrm{w})$ and high ionic strength $(50 \mathrm{mM}$ to $1000 \mathrm{mM} \mathrm{NaCl})$ on the rheology of carboxymethylated (NFC-carb) and 2,2,6,6-tetramethylpiperidine-1-oxyl (TEMPO) oxidized (NFC-TEMPO) nanofibrillated cellulose (NFC) suspensions were studied. Morphological characterization and centrifugation showed that NFC-TEMPO had a much finer overall morphology than NFC-carb. Rheological measurements were taken at 1.3 wt $\%$ using a stress-controlled rheometer equipped with cone and plate measurement tools with rough surfaces. The dynamic moduli were investigated through oscillatory stress sweeps. The results showed that as little as $2.5 \%(\mathrm{w} / \mathrm{w})$ of either ethanol or acetone decreased the viscosity and the dynamic moduli, while $40 \%(\mathrm{w} / \mathrm{w})$ increased the viscosity to values higher than those of the aqueous suspensions, doubled the storage modulus, and extended the gel-like behavior. Increasing the $\mathrm{NaCl}$ concentration from $50 \mathrm{mM}$ to $100 \mathrm{mM}$ drastically increased viscosity; moreover, the storage modulus in the elastic region linearly increased with increasing $\mathrm{NaCl}$ concentrations in the range of $100 \mathrm{mM}$ to $1000 \mathrm{mM}$, suggesting the increased content of interparticle bonds with $\mathrm{NaCl}$ addition. The elastic domain was also extended from $10 \mathrm{~Pa}$ to $50 \mathrm{~Pa}$ and above 500 $\mathrm{Pa}$ with acetone addition (40\%) and $\mathrm{NaCl}$ addition, respectively.

Keywords: Nanofibrillated cellulose; Rheology; Morphology; High ionic strength; Ethanol/acetone addition

Contact information: Department of Chemistry, Unit of Fiber Materials and Environmental Technologies (FibEnTech-UBI), University of Beira Interior, 6200-001 Covilhã, Portugal;

* Corresponding author: rmss@ubi.pt

\section{INTRODUCTION}

Many biological materials exhibit impressive and controllable properties determined by their micro- and nanostructures (Bhushan and Jung 2011).

Nanofibrillated cellulose (NFC) is a cellulosic material with lateral dimensions usually under $100 \mathrm{~nm}$, which is typically obtained via mechanical defibrillation of wood pulp, commonly preceded by enzymatic treatments (Janardhnan and Sain 2006; Henriksson et al. 2007; Pääkkö et al. 2007) and/or chemical treatments such as 2,2,6,6tetramethylpiperidine-1-oxyl (TEMPO)-mediated oxidation (Saito et al. 2007), aqueous morpholine addition (Onyianta et al. 2018), carboxymethylation (Wagberg et al. 2008; Naderi and Lindstrom 2014), or sulfoethyltion (Naderi et al. 2017). These treatments result in a gel-like cellulosic aqueous suspension.

NFC recently has been the subject of much attention due to its unique characteristics, such as high aspect ratio and mechanical resistance, as well as its aptitude to set up strong entangled networks with high transparency (Nechyporchuk et al. 2016). In addition, NFC is a renewable and biodegradable material, among other attributes, which makes it suitable for many industrial applications, namely as a reinforcing phase in composites and in fields such as packaging, adhesives, biomedicine, etc. (Nechyporchuk 
et al. 2016). The potential of NFC, cellulose nanocrystals and bacterial cellulose in packaging applications was also recently reviewed (Hubbe et al. 2017a).

The manipulation and application of NFC suspensions requires the study of their rheological behavior. Thus, research has been lately focused on the determination of the dynamic moduli (storage modulus: $G$ ' and loss modulus: $G$ ') from the linear viscoelastic regions during oscillation measurements, as well as viscosity $(\eta)$ and/or shear stress $(\tau)$ during flow measurements (Naderi et al. 2014a,b; Nechyporchuk et al. 2014).

It has been reported that the NFC suspensions' rheological properties are highly concentration dependent (Pääkkö et al. 2007; Karppinen et al. 2012; Chen et al. 2013; Nechyporchuk et al. 2015); even at solid concentrations as low as $0.125 \mathrm{wt} \%$, the suspensions exhibit a shear-thinning thixotropic behavior and gel-like properties, i.e., the rheological response of the suspension is elastic dominated $\left(G^{\prime} \gg G^{\prime}\right.$ ') (Pääkkö et al. 2007; Nechyporchuk et al. 2015). However, more recently, Fneich et al. (2019) stated $0.25 \%$ as the optimal solid content at which the gel-like behavior appears for a salt-free suspension although the gel-like behavior can be attained at $0.1 \%$ in the presence of 50 $\mathrm{mM} \mathrm{NaCl}$.

Apart from the solid concentration, other features that have been reported to affect the rheological properties of NFC suspensions include morphological characteristics such as the length of the nanofibrils, their aspect ratio (Ishii et al. 2011; Iwamoto et al. 2013; Benhamou et al. 2014; Tanaka et al. 2014, 2015), pH, temperature, and the ionic strength of the medium (Karppinen et al. 2012; Saarikoski et al. 2012; Naderi and Lindstrom 2014; Tanaka et al. 2016, Hubbe et al. 2017b).

Regarding the effect of ionic strength on viscosity and viscoelastic properties, apparent contradictory conclusions have been suggested by Mendoza et al. (2018). Naderi and Lindstrom (2014), working with carboxymethyl cellulose with a charge of $590 \mu \mathrm{eq} / \mathrm{g}$ of carboxyl groups at $1 \%$ solid content and a $\mathrm{NaCl}$ concentration in the range of 0 to 10 $\mathrm{mM}$, reported a decrease in both the viscosity and the elastic moduli. Fukuzumi et al. (2014) explored a broader range of $\mathrm{NaCl}$ concentration ( 0 to $400 \mathrm{mM})$ and worked with TEMPO-oxidized cellulose at a $0.1 \%$ solid content and reported no significant decrease in the viscosity until $10 \mathrm{mM}$ of $\mathrm{NaCl}$, but also reported a drastic increase in viscosity between $10 \mathrm{mM}$ and $100 \mathrm{mM} \mathrm{NaCl}$ followed by a moderate decrease thereafter. Saarikoski et al. (2012) also reported a very moderate increase in the storage modulus with $\mathrm{NaCl}$ concentration in the range 0 to $1 \mathrm{M}$ for a very low surface-charge on microfibrillated cellulose (MFC). Tanaka et al. (2014) also reported an increase in the storage modulus with salt addition. The same research group, working with NFC having a substantially different carboxyl group content $(200 \mu \mathrm{mol} / \mathrm{g}$ and $900 \mu \mathrm{mol} / \mathrm{g})$, but simultaneously with different hemicellulose content, suggested that the carboxyl groups content has a role on the sensitivity of the salt concentration and its effect on the storage modulus (Tanaka et al. 2016). More recently, Xu et al. (2018) identified two types of solid-phases for cellulose nanocrystals suspensions: a repulsive phase at low salinity and an attractive solid phase at high salinities.

It has also been reported that inherent flow instabilities occur during rheological studies of NFC suspensions. These instabilities introduce errors in the rheological measurements: shear banding and wall-slip phenomena, also designated by wall depletion, which creates a lubrication effect and results in a lower energy state during laminar shearing (Ovarlez et al. 2009; Saarinen et al. 2009; Nechyporchuk et al. 2014). Shear banding arrives from a dynamic situation of competition between flock formation vs. consolidation over time and flock destruction due to flow, favoring fragments segregation and leading to coexisting fast and slow flowing regions. Wall depletion consists of interfacial slippage on the edge of geometry tools and the suspension due to a displacement of a disperse phase from solid boundaries. To prevent or decrease these flow instabilities, 
many methods have been used, such as increasing the gap (Saarinen et al. 2009), using other geometry configurations like a vane-in-cup system (Mohtaschemi et al. 2014), or using roughened tool surfaces that take advantage of the material's cohesive forces (Naderi and Lindstrom 2015; Nechyporchuk et al. 2015).

Although NFC are mostly produced and processed in aqueous media, organic solvents, such as ethanol or acetone, can play a role in solvent exchange for processing, as the reaction medium for derivatization, and even as the coagulation medium in wetspinning. In fact, several authors (Iwamoto et al. 2011; Håkansson et al. 2014) have reported the use of acetone as a coagulation or exchange medium. As far as the authors know, the rheological response to the addition of organic solvents, like ethanol, to NFC suspensions has not been yet investigated. In contrast, the effect of ionic strength of NFC suspensions on viscosity and viscoelastic behavior has been extensively reported, but some contradictory results remain, probably due to the different nanocellulose characteristics, including surface charge, the ranges of ionic strength, and studied solid contents.

Therefore, the objectives of this investigation are to study the effects of organic solvent addition (ethanol or acetone) to the NFC aqueous medium and the effect of $\mathrm{NaCl}$ concentration in the range of $100 \mathrm{mM}$ to $1000 \mathrm{mM}$ on flow and dynamic rheological behavior of two strongly different NFC suspensions, including morphological and carboxylate content levels.

\section{EXPERIMENTAL}

\section{Materials}

For this study, a carboxymethylated NFC aqueous suspension containing a $2.2 \mathrm{wt} \%$ solid content, obtained from Innventia (Stockholm, Sweden), was used. This suspension will be designated as NFC-carb in the study.

An NFC suspension was also produced in the authors' lab from a commercial bleached sulphite eucalyptus pulp. The pulp was subjected to a TEMPO-mediated oxidation pretreatment under previously reported reaction conditions (Saito et al. 2007) and then subjected to two successive homogenization steps (500 bar and 1000 bar), using a GEA Niro Soavi (model Panther NS3006L; GEA, Parma, Italy). The solid content of the suspension was initially kept at $1 \%$; afterwards, the solids content was increased to approximately $2.2 \%$ via evaporation at room temperature with occasional stirring; when required, additional water was removed from the gel by absorption using blotting paper. The obtained NFC from this process will henceforth be called NFC-TEMPO.

\section{Methods}

\section{Microscopic observations}

The NFC-carb and NFC-TEMPO suspensions were diluted with distilled water to attain a solid content of $0.1 \mathrm{wt} \%$ and were subsequently sonicated for $5 \mathrm{~min}$ to improve the dispersion of the fibrils. A drop of each diluted suspension was allowed to air dry overnight at room temperature on a microscopic slide, and it was later attached on a microscope sample holder with double-sided tape. Microscopic observations were performed using scanning electron microscopy (SEM) (Hitachi S-2700; Hitachi, Tokyo, Japan) operated at $20 \mathrm{kV}$. All of the samples were previously gold-sputtered by cathodic spraying (Quorum Q150R ES; Quorum Technologies, Ltd., East Sussex, UK).

For the transmission electron microscope (TEM) imaging, drops of $0.001 \mathrm{wt} \%$ NFC-carb and NFC-TEMPO suspensions were deposited on carbon-coated electron microscopic grids and negatively stained with $2 \mathrm{wt} \%$ uranyl acetate. The grids were air- 
dried and analyzed with a Hitachi HT-7700 TEM (Hitachi, Tokyo, Japan) with an acceleration voltage of $80 \mathrm{kV}$.

\section{NFC carbohydrate composition}

The neutral sugar compositions of NFC-carb and NFC-TEMPO suspensions were determined by quantitative saccharification upon acid hydrolysis according to the National Renewable Energy Laboratory's (NREL) proceeding guidelines for the determination of structural carbohydrates and lignin in biomass (Sluiter et al. 2012). Thin layers of NFCcarb and NFC-TEMPO were oven-dried at $50{ }^{\circ} \mathrm{C}$ for $4 \mathrm{~h}$ and were finely fragmented with scissors prior to the acid hydrolysis. The structural carbohydrates were quantified using an HPLC system that integrates a pump (Perkin Elmer Binary LC Pump 250; Perkin Elmer, Waltham, MA, USA), equipped with an UV/Vis detector (LC290; Perkin Elmer, Waltham, MA, USA), a refraction index detector (HP 1047A RI Detector; Hewlett Packard, Palo Alto, CA, USA) and a liquid chromatography column (Aminex HPX-87H; Bio-Rad Laboratories, Inc., Hercules, CA, USA).

\section{Degree of polymerization in NFC polysaccharides}

The determination of the NFC limiting viscosity $[\eta]$, was achieved with a cupriethylenediamine (CED) solution as a solvent, using a capillary viscometer according to the ISO 5351 (2012) standard. The degree of polymerization (DP) was calculated using the Mark-Houwink-Sakurada equation $[\eta]=0.57 \times$ DP $($ Smith et al. 1963).

\section{Total acidic groups content in NFC}

The content of total acidic groups in NFC was determined via a conductivity titration method, according to the standard SCAN-CM 65:02 (2002). First, the NFC was suspended in an $\mathrm{HCl}$ solution to protonate the NFC. Due to filtration issues, the vacuum filtration washing after the protonation step was substituted by sequential 15 min centrifugations at $3000 \mathrm{~g}$. The supernatant was discarded and the process of adding distilled water and mixing after each centrifugation was continued until the supernatant attained a conductivity of $5 \mu \mathrm{S} / \mathrm{cm}$. The suspensions were afterwards titrated with a $\mathrm{NaOH}$ solution to $\mathrm{pH}=11$. The amount of weak acid groups was determined from break points in the conductivity vs. added volume of $\mathrm{NaOH}$ from the curves obtained from the conductivity titrations.

\section{Preparation of the NFC suspensions for rheological measurements}

Suspensions of NFC with $1.30 \mathrm{wt} \%$ solid content were produced from the original NFC-carb and NFC-TEMPO through the addition of the appropriate amount of distilled water, organic solvent, or $\mathrm{NaCl}$ aqueous solutions. The homogenization of the suspension was obtained through vigorous agitation in a vortex mixer with four successive steps lasting 1.0 min each with handshaking in-between.

Ethanol or acetone were added to the original NFC aqueous suspensions to attain the suspension medium with ethanol/(ethanol + water) percentages of $2.5 \%, 5.0 \%, 10.0 \%$, $20.0 \%$, and $40.0 \%(\mathrm{w} / \mathrm{w})$. The $\mathrm{NaCl}$ solutions were added to attain the final concentrations of $5 \mathrm{mM}, 100 \mathrm{mM}, 300 \mathrm{mM}, 500 \mathrm{mM}$, and $1000 \mathrm{mM}$.

Prior to the rheological measurements, all suspensions were sonicated for $5 \mathrm{~min}$ to ensure proper homogenization and air bubble removal. After this step, the NFC suspensions were loaded in the rheometer and rested for $1.0 \mathrm{~min}$ before the rheological assays. The samples were not subjected to preshearing in the rheometer with the purpose of avoiding the distortion of the initial NFC structure before the measurements (Nechyporchuk et al. 2015). 


\section{Zeta potential measurements}

The previously prepared $1.3 \mathrm{wt} \%$ NFC-carb and NFC-TEMPO suspensions with $\mathrm{NaCl}$ concentrations of $0 \mathrm{mM}, 50 \mathrm{mM}, 100 \mathrm{mM}$, and $1000 \mathrm{mM}$, as well as NFC-carb suspensions with $2.5 \%$ and $40 \%$ (w/w) ethanol were diluted to a solids content of $0.1 \mathrm{wt} \%$ with distilled water, the $\mathrm{pH}$ was adjusted to 7 , and the resulting suspensions were sonicated for $5 \mathrm{~min}$. A rough estimative of the surface particles charge was obtained by a streaming current detector (Mütek PCD-02; BTG Product Digest, Herrsching, Germany).

\section{Rheological measurements}

The rheological measurements were recorded using a stress-controlled rheometer (RheoStress ${ }^{\circledR}$ RS 150; Haake Technik GmbH, Vreden, Germany). A cone and plate geometry with a $2^{\circ}$ angle cone sensor $\left(\mathrm{C} 35-2^{\circ}\right)$ with a diameter of $35 \mathrm{~mm}$ and a gap of $0.105 \mathrm{~mm}$ were used to study the NFC suspensions in both flow and oscillation modes. To study the effect of the tool's roughness on the rheological measurements, a sandpaper with a roughness of either $58.5 \mu \mathrm{m}$ or $18.3 \mu \mathrm{m}$, depending on the assay, was attached to both the plate and cone using double-sided tape. When roughened surfaces were used, the thickness of the sand paper was taken into account, maintaining the same gap as in the assays with smooth surfaces. To minimize water or ethanol evaporation, all of the rheological measurements were performed under a homemade transparent cover.

In flow mode, controlled rate flow tests were conducted with a shear rate $(\gamma)$ in the range of $0.05 \mathrm{~s}^{-1}$ to $1000 \mathrm{~s}^{-1}$ for $180 \mathrm{~s}$. Shear stress $(\tau)$ and viscosity $(\eta)$ were analyzed.

The viscoelastic behavior was studied through oscillatory stress sweeps performed with a $\tau$ in the range of $0.07 \mathrm{~Pa}$ to either $100 \mathrm{~Pa}$ or $10000 \mathrm{~Pa}$, depending on the suspension's rheological performance, with a frequency of $1.0 \mathrm{~Hz}$. The dynamic moduli $\left(G^{*}\right)$, i.e., the storage modulus $\left(G^{\prime}\right)$ and the loss modulus $\left(G^{\prime}\right.$ ') were analyzed. The suspensions were tested at room temperature $\left(22 \pm 1{ }^{\circ} \mathrm{C}\right)$. All of the described assays were performed in duplicate and the results represent the arithmetic average in each point.

\section{RESULTS AND DISCUSSION}

\section{Morphological Characterization of the Fibrils}

The morphology of the fibrils was investigated through SEM and TEM analyses using various magnifications to capture the micro- and nano-scale particles. Figure 1 gives an overview of the morphological characteristics of the NFC-carb and NFC-TEMPO fibrils.

As shown in Figs. 1a and 1c, the fibrillation of the material appears not to have been homogeneous and particularly incomplete, especially for NFC-carb. Although the fine fibrillar structures with diameters in the nanometer range can be spotted in both materials (Figs. 1b and 1d), the relative proportion of the fibers with micrometer dimensions was clearly higher in NFC-carb. The pretreatments performed on NFCTEMPO led to a substantial deconstruction of the fibrillar cell wall of the sulphite eucalyptus pulp, thus resulting in shorter fibrillar structures and a finer overall morphology when compared to the NFC-carb fibrils produced from softwood kraft pulp.

To roughly quantify the relative proportions of nano- and microelements, extremely dilute suspensions $(0.05 \mathrm{wt} \%)$ of both materials were adjusted to a $\mathrm{pH}$ of 4 (to protonate most parts of the carboxylate groups; $\mathrm{pKa}=4.8$ ) and were submitted to centrifugation at $9000 \mathrm{~g}$ for $20 \mathrm{~min}$. The obtained sedimented material was quantified. The experimental results showed nearly $84 \%$ and $57 \%$ of the initial material has sedimented for NFC-carb and NFC-TEMPO, respectively, confirming the higher percentage of nanoelements in NFC-TEMPO. Therefore, the two materials had substantially different morphological 
properties. While most of the NFC-carb's elements were predominantly at microscale range, the NFC-TEMPO's were made up of many more elements in the nanoscale range.
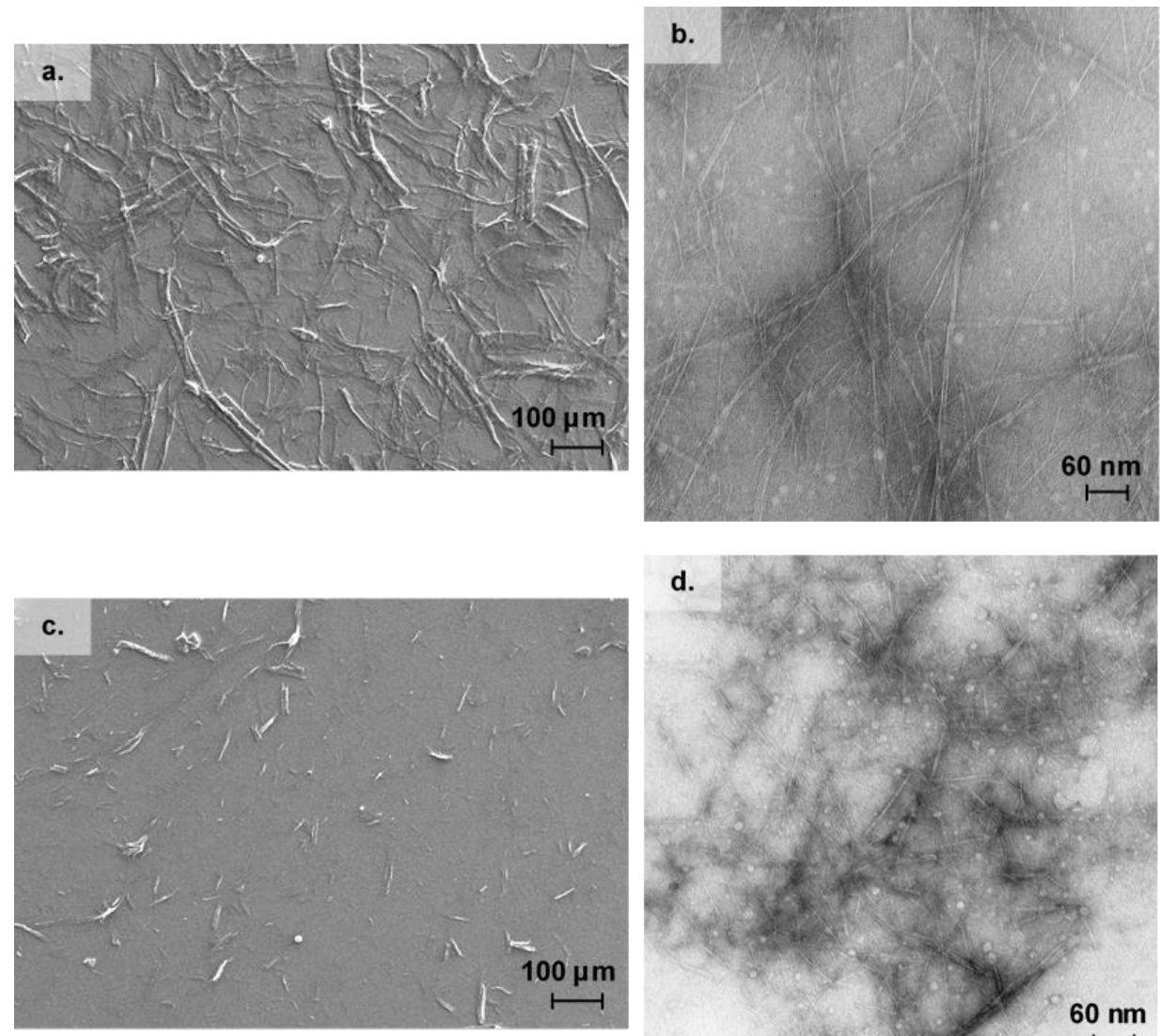

d.

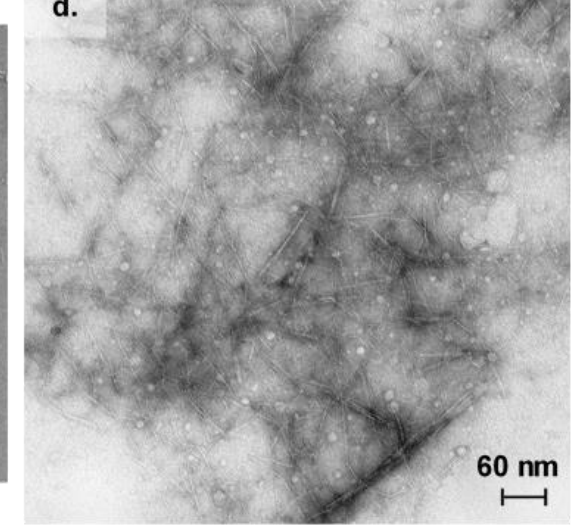

Fig. 1. NFC-carb ( $a$ and $b$ ) and NFC-TEMPO ( $c$ and d) fibrils imaged through SEM (a and $c$ ) at a solid content of $0.1 \mathrm{wt} \%$ and TEM ( $b$ and $d$ ) at a solid content of $0.01 \mathrm{wt} \%$

\section{Physico-chemical Characterization of the Fibrils}

The structural carbohydrates in NFC-carb were quantified through acid saccharification. The material was made up of $88.4 \%$ cellulose and approximately $11.6 \%$ hemicelluloses. The NFC-carb's limiting viscosity was $397 \mathrm{~mL} / \mathrm{g}$, which corresponded to an average DP of 696, suggesting a good preservation of the DP of the initial raw materials. Assuming that the weak acidic groups were predominantly carboxylic acid groups introduced during the carboxymethylation pretreatment stage in the course of the NFC production, its carboxyl group content was determined as $698 \mu \mathrm{mol} / \mathrm{g}$. This value was in good agreement with those reported by NFC produced via a similar process (Naderi et al. 2014a).

Concerning the NFC-TEMPO material, the resulting limiting viscosity was 85 $\mathrm{mL} / \mathrm{g}$, corresponding to an average DP of 149, and the resulting carboxyl group content was $1900 \mu \mathrm{mol} / \mathrm{g}$. Both the carboxylic group content and the polysaccharides' DP were in good agreement with the values reported in the literature for similar pretreatments (Shinoda et al. 2012). From Fig. 1 and the physicochemical data, it was clearly demonstrated that the two materials used in the present work were representatives of two morphologically and physio-chemically different materials.

\section{Effect of Geometry Surface Roughness}

Many authors have reported that a distortion of the rheological measurements of NFC suspensions (mostly during flow mode measurements) occurs due to wall-slip 
phenomena and hence at least one roughened or serrated tool surface was introduced to overcome this issue (Iotti et al. 2011; Naderi et al. 2014b; Nechyporchuk et al. 2014; Nechyporchuk et al. 2015). For example, Nechyporchuk et al. (2014) have suggested attaching sandpaper (roughness of approximately $120 \mu \mathrm{m}$ ) on the surfaces of cone and plate measurement tools to prevent wall-slippage of a $1.0 \mathrm{wt} \%$ TEMPO-oxidized NFC suspension during rheological flow measurements. In the present study, preliminary rheological studies were performed to determine the influence of different surface roughness on the measurements. Sandpapers with various roughness values $(58.5 \mu \mathrm{m}$ and $18.3 \mu \mathrm{m})$ were attached to the surface of both the plate and sensor. Controlled rate flow assays were performed with both mentioned sandpapers and also without the sandpaper (smooth surface) using a $1.3 \mathrm{wt} \%$ NFC-carb aqueous suspension.
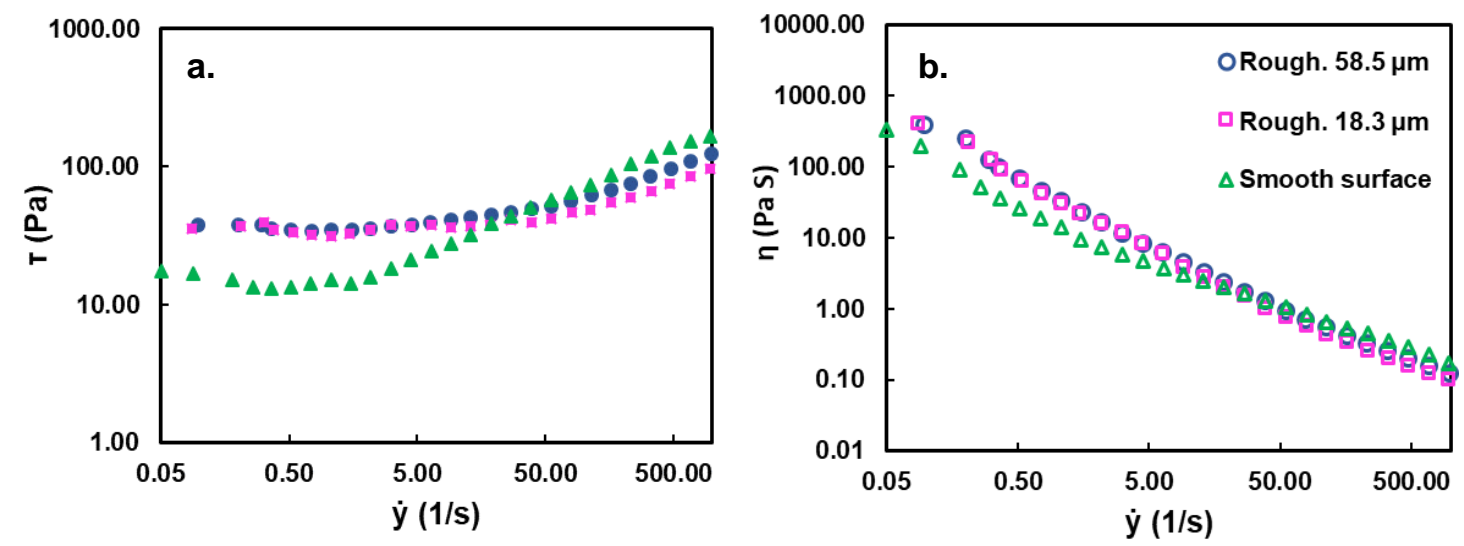

Fig. 2. Shear stress (a) and viscosity (b) curves of a 1.3 wt\% NFC-carb aqueous suspension performed with smooth, $58.5 \mu \mathrm{m}$, and $18.3 \mu \mathrm{m}$ roughened surfaces

Figure 2 shows the stress rate flow curves of a 1.3 wt\% NFC-carb aqueous suspension, performed with various surface roughness, where it was evident that both the measured shear stress and viscosity were higher when the assay was performed with roughened surfaces, particularly at shear rates between $0.05 \mathrm{~s}^{-1}$ and $5 \mathrm{~s}^{-1}$. The results were in good agreement with those obtained by Nechyporchuk et al. (2014, 2015); however, these authors reported that wall-slip can still occur with roughened surfaces $(\approx 120 \mu \mathrm{m})$ for the enzymatically pretreated NFC and attributed this effect to the water release from the suspension, which probably does not occur in the present case due to the higher carboxyl group content.

In accordance with what was reported by other authors, at higher shear rates (from $10 \mathrm{~s}^{-1}$ to $100 \mathrm{~s}^{-1}$ ) the measurements were less influenced by the flow instabilities as well as the used geometries and their roughness, closely representing the bulk properties of the NFC suspensions (Haavisto et al. 2014; Nechyporchuk et al. 2015).

Because no substantial variation was detected between the results for the two different roughness levels (Fig. 2), the authors believe that the size of the sandpaper grain did not play an important role in keeping the cohesive forces between the bulk of the suspension and the borders for the used roughness. In fact, other authors have reported that to avoid wall-slip, the texture of the roughened surfaces only needs to be on the same scale of the studied particle size, even though exceeding this value, on the side of caution, might be prudent (Buscall 2010; Naderi and Lindström 2015). In the following assays, only measurements made with the $58.5 \mu \mathrm{m}$ roughness sandpaper was described if nothing was otherwise mentioned. 
Regarding the flow curves (Fig. 2), it was possible to clearly identify a plateau in the shear stress for a shear rate in the range of $0.05 \mathrm{~s}^{-1}$ to $10 \mathrm{~s}^{-1}$, which translated to a decrease in apparent viscosity.

\section{Effect of Ethanol and Acetone Concentrations in the Suspension Medium}

Organic solvents, such as ethanol and acetone, have been widely used in coagulation and fixation baths for the production of NFC filaments from aqueous suspensions via wet spinning (Iwamoto et al. 2011; Walther et al. 2011; Håkansson et al. 2014) and dry jet-wet spinning (Hauru et al. 2014); to the authors' knowledge, no rheological study has been conducted on NFC suspensions containing these solvents. Although the NFC fibrils are assumed to make the major contribution to the rheological effects, the rheological behavior of the suspending medium, and mainly its interaction with fibrils, surely play a key role.

To evaluate the effect of ethanol and acetone additions on the rheological behavior of NFC suspensions, controlled rate flow assays and oscillatory stress sweeps were performed on the NFC-carb suspensions with various contents of either ethanol or acetone.
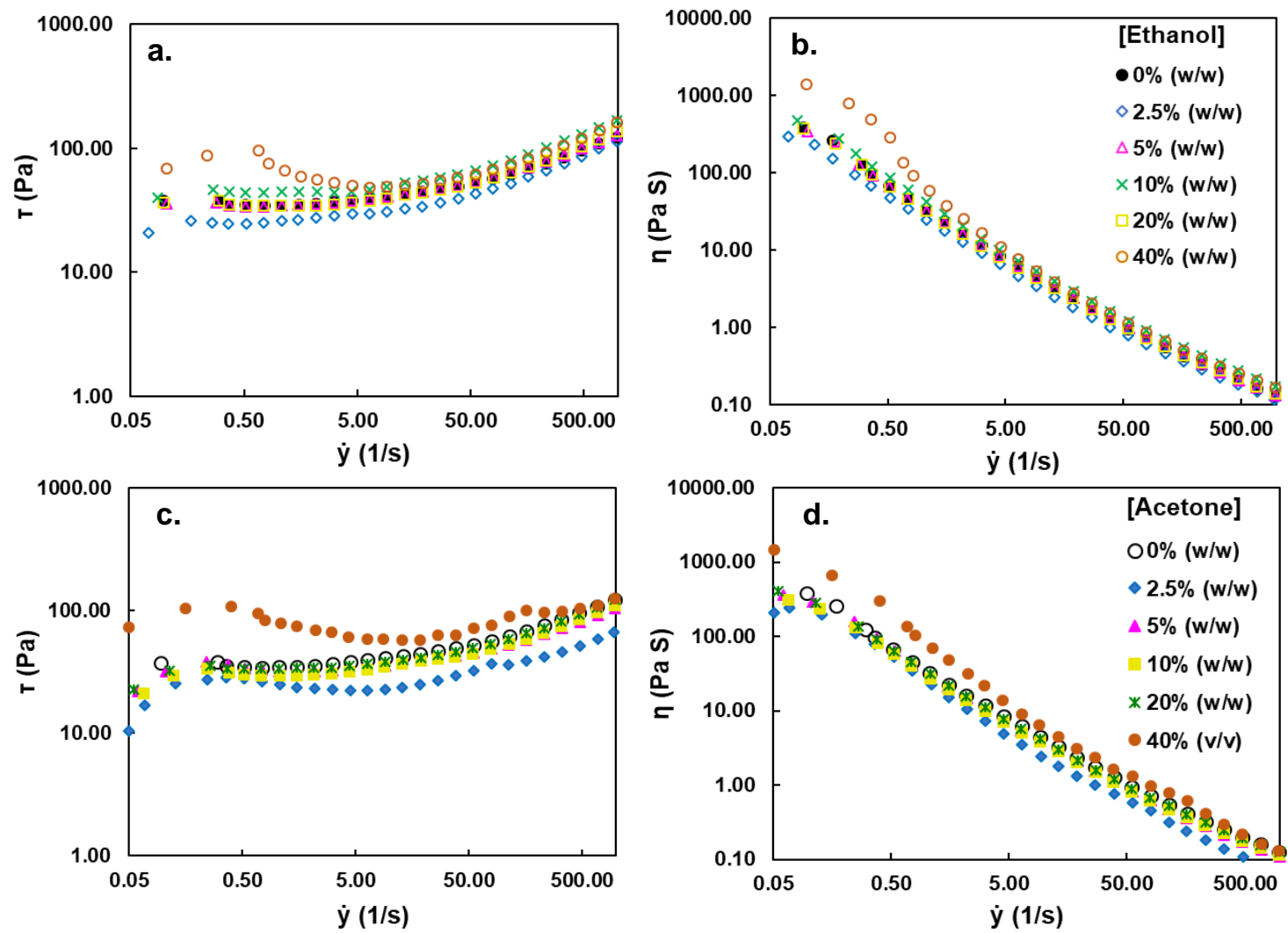

Fig. 3. Shear stress ( $a$ and $c$ ) and viscosity ( $b$ and d) flow curves of 1.3 wt\% NFC-carb suspensions with $0 \%, 2.5 \%, 5 \%, 10 \%, 20 \%$, and $40 \%(\mathrm{w} / \mathrm{w})$ of ethanol $(\mathrm{a}$ and $\mathrm{b})$ and acetone (c and d)

Figure 3 shows the stress rate flow curves of $1.3 \mathrm{wt} \%$ NFC-carb suspensions with $0 \%, 2.5 \%, 5 \%, 10 \%, 20 \%$, and $40 \%(\mathrm{w} / \mathrm{w})$ of either ethanol or acetone, performed with roughened surfaces. It was observed that a small concentration of either ethanol or acetone $(2.5 \%(\mathrm{w} / \mathrm{w}))$ somewhat decreased the shear stress and viscosity of the suspensions, probably due to an impairing of the hydrogen bonds between fibrils. However, an organic solvent concentration as high as $40 \%$ (w/w) increased the shear stress values considerably higher than those of the pure aqueous suspensions, predominantly at low and moderate 
shear rates, showing higher interfibrillar interaction and viscosity. The decreasing value of the dielectric constant of the bulk solvent as the concentration of ethanol or acetone increased could explain the cohesion of the suspension. This topic will be further discussed in the paper.

Oscillatory assays were performed on the same suspensions (Fig. 4).
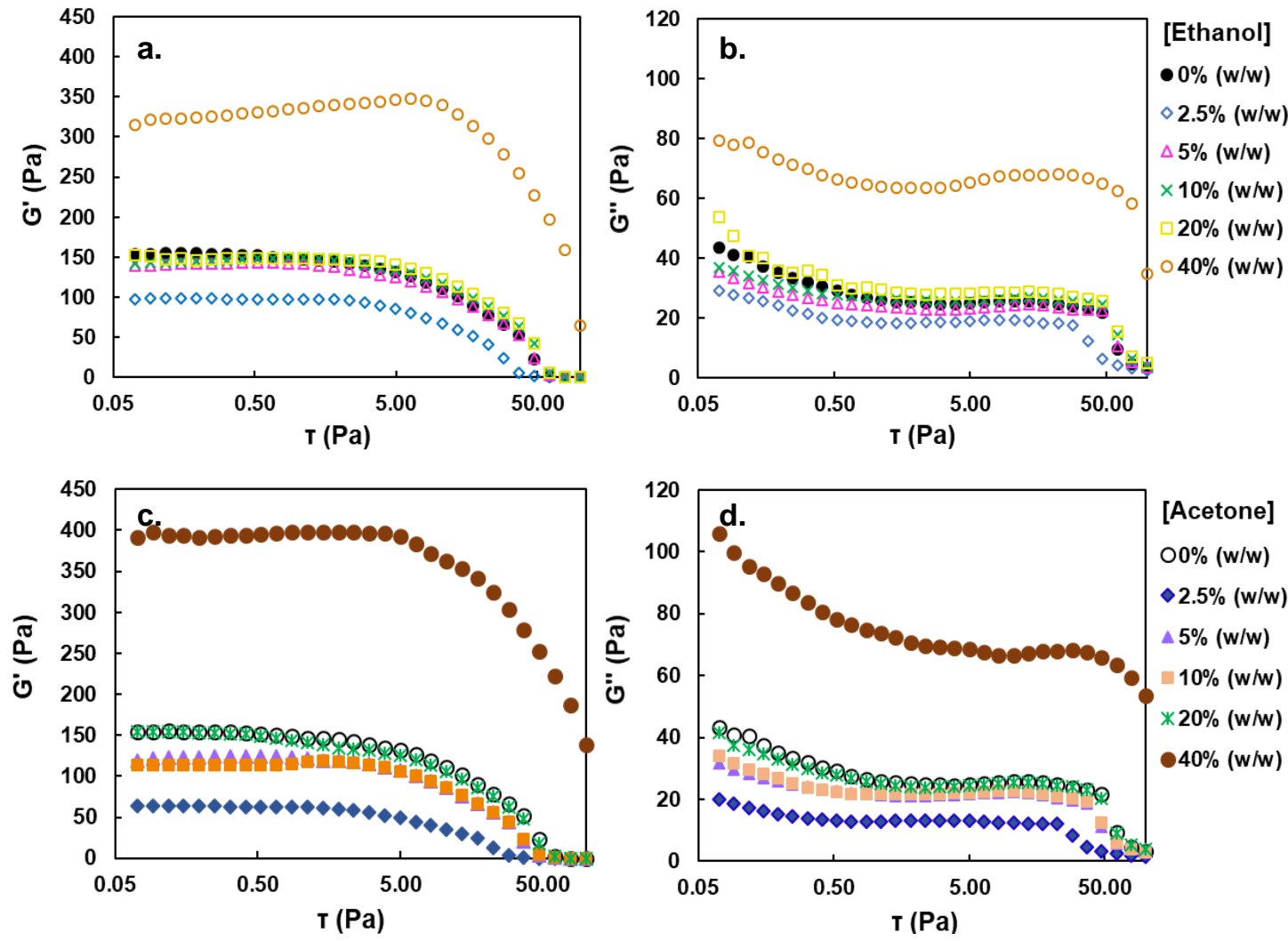

Fig. 4. Storage modulus ( $a$ and $c$ ) and loss modulus ( $b$ and $d$ ) of oscillatory stress sweep curves of $1.3 \mathrm{wt} \%$ NFC-carb suspensions with $0 \%, 2.5 \%, 5 \%, 10 \%, 20 \%$, and $40 \%(\mathrm{w} / \mathrm{w})$ of ethanol ( $a$ and $b$ ) and acetone (c and d)

The dynamic rheology was measured using a stress-controlled rheometer instead of the more usual strain-controlled rheometer. In the latter case, for a fixed strain, the oscillation frequency is changed while the dynamic moduli are monitored. In this study, at a fixed frequency $(1.0 \mathrm{~Hz})$, the shear stress was changed and the corresponding moduli were recorded. In this solicitation mode, the material was simultaneously submitted to both higher shear stress (and corresponding shear rate) and strain at the fixed frequency.

The results from this study allowed the estimation of the shear stress endured by the gel before the structure completely breaks down. The loss tangent $(\tan \delta)$ values in Fig. 5 , which were calculated through the ratio $\left(G^{\prime} / G^{\prime}\right)$ of the loss modulus $\left(G^{\prime}\right.$ ') to the elastic modulus $\left(G^{\prime}\right)$, identified three profiles: (i) the suspension with a small amount of acetone or ethanol, which started to lose elasticity for lower shear stress values; (ii) the $40 \%$ ethanol or acetone NFC suspensions, which clearly retained their elastic behavior until higher shear stress values; and (iii) all the remaining suspensions with intermediate elastic behavior. In short, it was clear that the addition of $40 \%$ of ethanol or acetone enabled further extension of the solid-like behavior to higher shear stress values. 

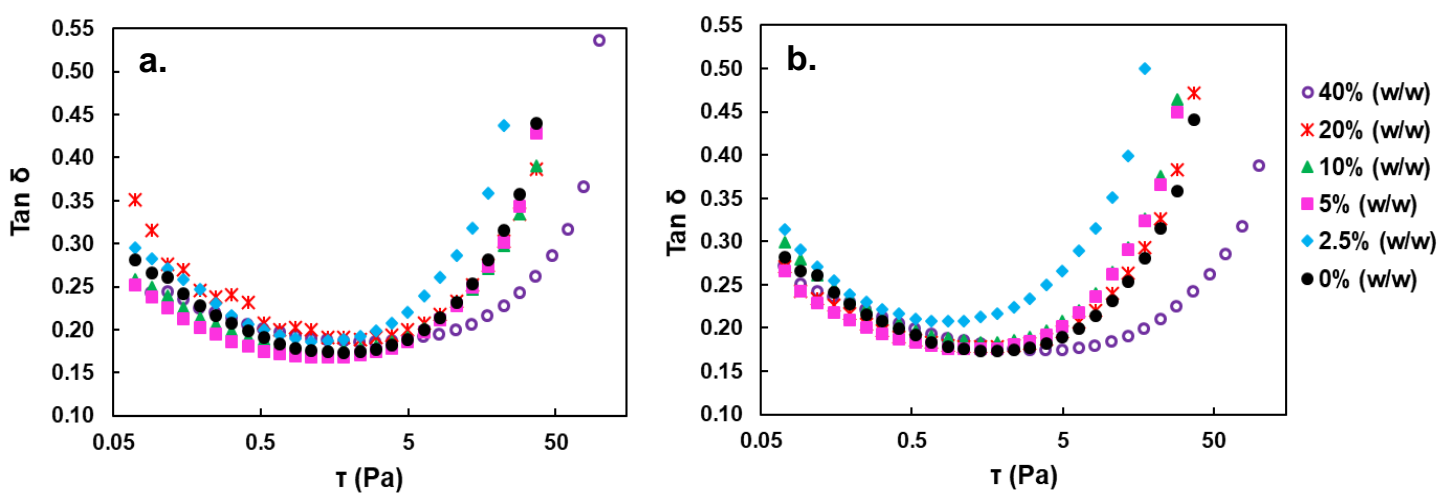

Fig. 5. Loss tangent values of 1.3 wt $\%$ NFC-carb suspensions with $0 \%, 2.5 \%, 5 \%, 10 \%, 20 \%$, and $40 \%(\mathrm{w} / \mathrm{w})$ of ethanol (a) and acetone (b)

According to Fig. 4, in the elastic domain, a small amount of ethanol or acetone $(2.5 \% \mathrm{w} / \mathrm{w})$ caused a decrease in the storage modulus (and viscosity as well) of the suspensions (from $150 \mathrm{~Pa}$ to $100 \mathrm{~Pa}$ for ethanol and to $50 \mathrm{~Pa}$ for acetone), which suggested a destabilization of the hydrogen bonds, weakening the fiber network. In contrast, concentrations of ethanol and acetone as high as $40 \%(\mathrm{w} / \mathrm{w})$ drastically increased the storage modulus from approximately $150 \mathrm{~Pa}$ to $350 \mathrm{~Pa}$ for ethanol and $400 \mathrm{~Pa}$ for acetone, respectively. Figure 6 represents the evolution of the output of the streaming potential detector corresponding to the particles with ethanol content of the medium, where an increased absolute value of $\zeta$-potential for $2.5 \% \mathrm{w} / \mathrm{w}$ ethanol was observed (from 1175 to 1420). This condition corresponded to a decrease in the storage modulus and viscosity, probably due to the increased repulsion between the particles. The streaming current detector output recovered for $5 \%$ of ethanol and remained relatively stable until $20 \%$ of ethanol; the same trend occurred for the storage modulus (Fig. 4). However, this property increased substantially for $40 \%$ of ethanol while the streaming current detector output (absolute value) substantially decreased to 565, diminishing the corresponding particles' electrostatic repulsion, whereas the van der Waals forces, including hydrogen bonds, were also revealed. The authors concluded that the effective particles' surface charge (as represented by the streaming current detector output) explained most of the storage modulus and the apparent viscosity variations well.

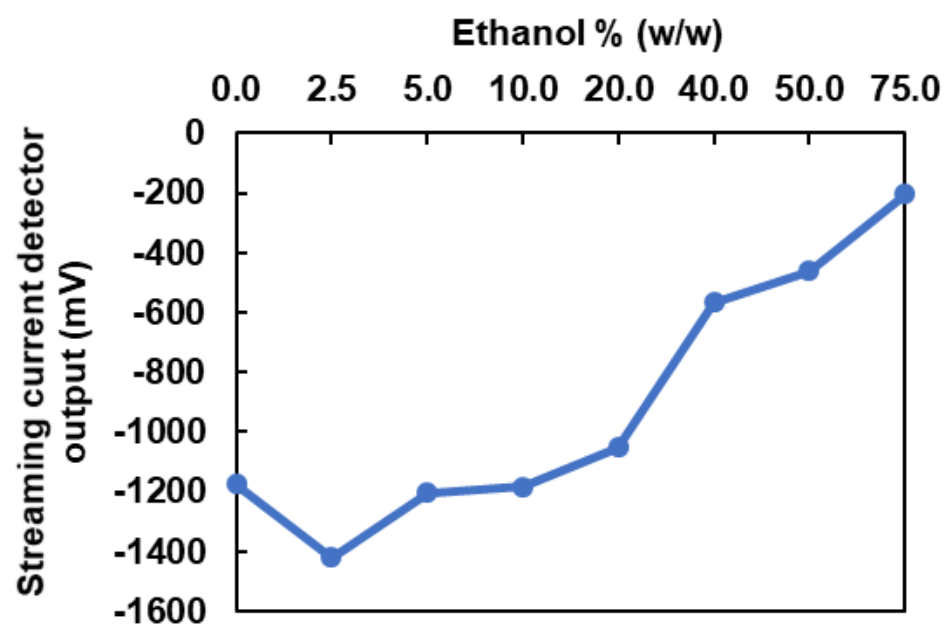

Fig. 6. Streaming current detector output of $0.1 \mathrm{wt} \%$ NFC-carb suspensions with $0 \%, 2.5 \%, 5 \%$, $10 \%, 20 \%$, and $40 \%(\mathrm{w} / \mathrm{w})$ of ethanol 
The ethanol concentration was further extended to $75 \%(\mathrm{w} / \mathrm{w})$, and the results for shear stress and storage modulus are presented in Fig. 7. The experimental results showed that an ethanol concentration of $75 \mathrm{wt} \%$ led to an extensive decrease in shear stress for the region with the high shear rate, which was observed as strong flocculation; instability was also observed in the storage modulus for a shear stress over $10 \mathrm{~Pa}$ and segregation of mainly water was evident under visual observation.
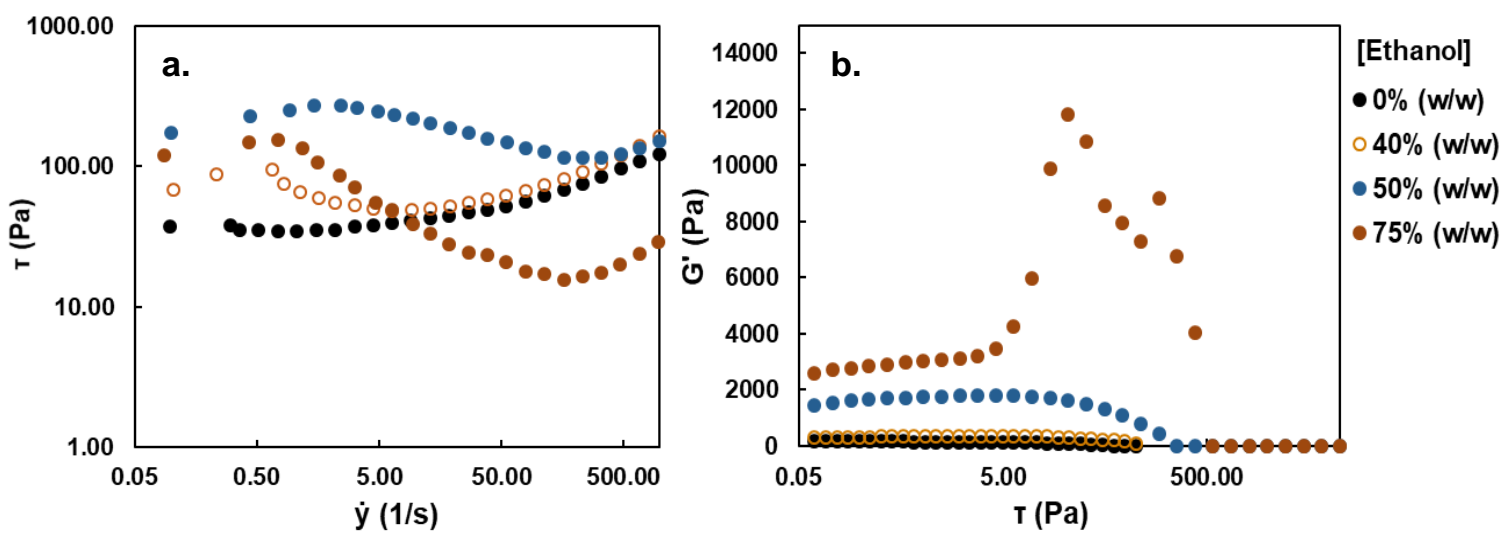

Fig. 7. Shear stress (a) and storage modulus (b) curves of $1.3 \mathrm{wt} \%$ NFC-carb suspensions with $0 \%, 40 \%, 50 \%$, and $75 \%(\mathrm{w} / \mathrm{w})$ of ethanol

\section{Effect of lonic Strength}

The effect of the ionic strength on the rheological behavior of NFC-carb aqueous suspensions was determined in both flow and oscillatory rheological experiments (Figs. 8 and 10), for a wide range of $\mathrm{NaCl}$ concentrations ( 0 to $1000 \mathrm{mM}$ ). Contrasting behaviors were observed when low (up to $50 \mathrm{mM}$ ) and high (100 mM and above) $\mathrm{NaCl}$ concentrations were explored. When the salt concentration increased from 0 to $50 \mathrm{mM}$, a decrease in viscosity was observed. Naderi and Lindstrom (2014) worked with carboxymethylcellulose having $590 \mu \mathrm{eq} / \mathrm{g}$ of carboxyl groups (an NFC similar to the authors' own NFC-carb) and reported a small decrease in both viscosity and storage modulus (measured at a solid content of $1 \%$ ) when the $\mathrm{NaCl}$ concentration was increased in the range 0 to $10 \mathrm{mM}$. Jowkarderis and Van de Ven (2014) also reported a similar decrease of intrinsic viscosity with ionic strength in the diluted regime. The behavior of samples in this study drastically changed when the salt concentration was increased to $100 \mathrm{mM}$, as can be seen in Fig. 8 . Jowkarderis and Van de Ven (2014) also reported an inversion of intrinsic viscosity at 20 $\mathrm{mM} \mathrm{NaCl}$ concentration, for a TEMPO-oxidized cellulose with a carboxyl content of 0.65 $\mathrm{mmol} / \mathrm{g}$.
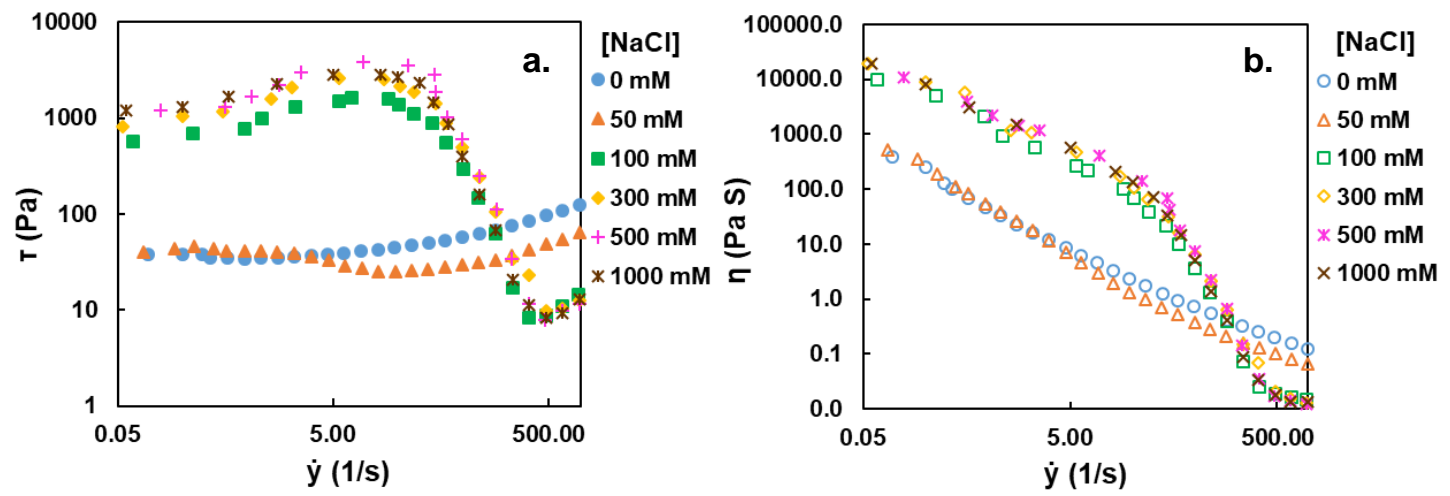

Fig. 8. Controlled rate flow curves of NFC- carb suspensions with various concentrations of $\mathrm{NaCl}$ : effect of ionic strength on the shear stress (a) and on the viscosity (b) 
Figure 8 shows that both the shear stress and viscosity drastically increased (close to two orders of magnitude) when the $\mathrm{NaCl}$ concentration was changed from $50 \mathrm{mM}$ to $100 \mathrm{mM}$; further increase in the $\mathrm{NaCl}$ concentration (until $1 \mathrm{M}$ ) had only a marginal effect. Moreover, observation of the suspension showed that up to a concentration of $50 \mathrm{mM}$ of $\mathrm{NaCl}$, the suspensions maintained their homogenous gel structure, but at higher $\mathrm{NaCl}$ concentrations a slight flocculation of the suspension was observed, which was in accordance with the decrease in the $\zeta$-potential (Fig. 9).

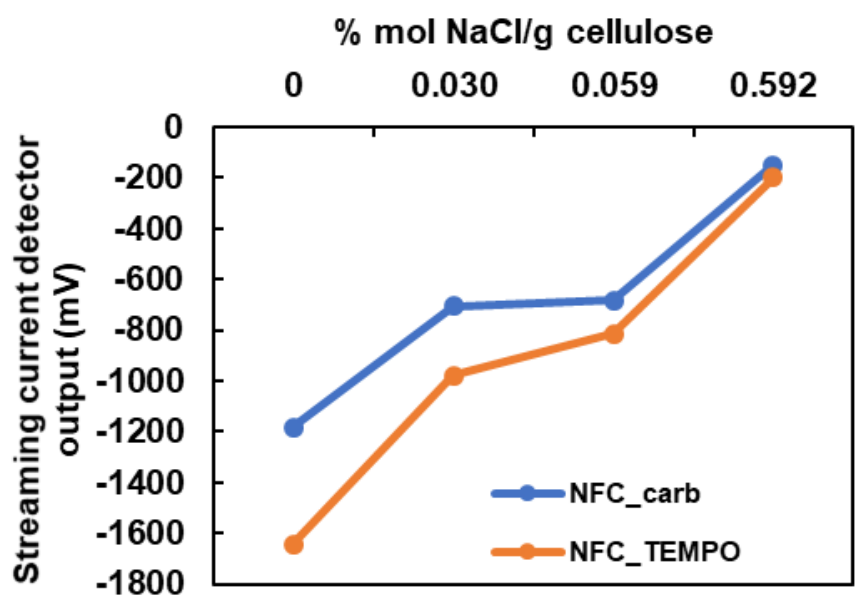

Fig. 9. Streaming current detector output for $0.1 \mathrm{wt} \%$ NFC-carb and NFC-TEMPO suspensions with increasing $\mathrm{NaCl}$ charges

The flocculation behavior, enhanced by the addition of $\mathrm{NaCl}$, was in accordance with that reported by Saarikoski et al. (2012). As expected, higher ionic strength increased the screening of the electrical charges in the fibrils surface, decreasing the electrostatic repulsion and thus allowing the fibrils to come closer together and strengthening the connection between the contact points. Another approach suggests that the salt neutralizes the carboxylate groups, leading to the same results (Fall et al. 2011). The results in Fig. 9 seem to support this view.

The comparative behavior of the two NFC suspensions (NFC-carb and NFCTEMPO) is presented in Fig. 10.
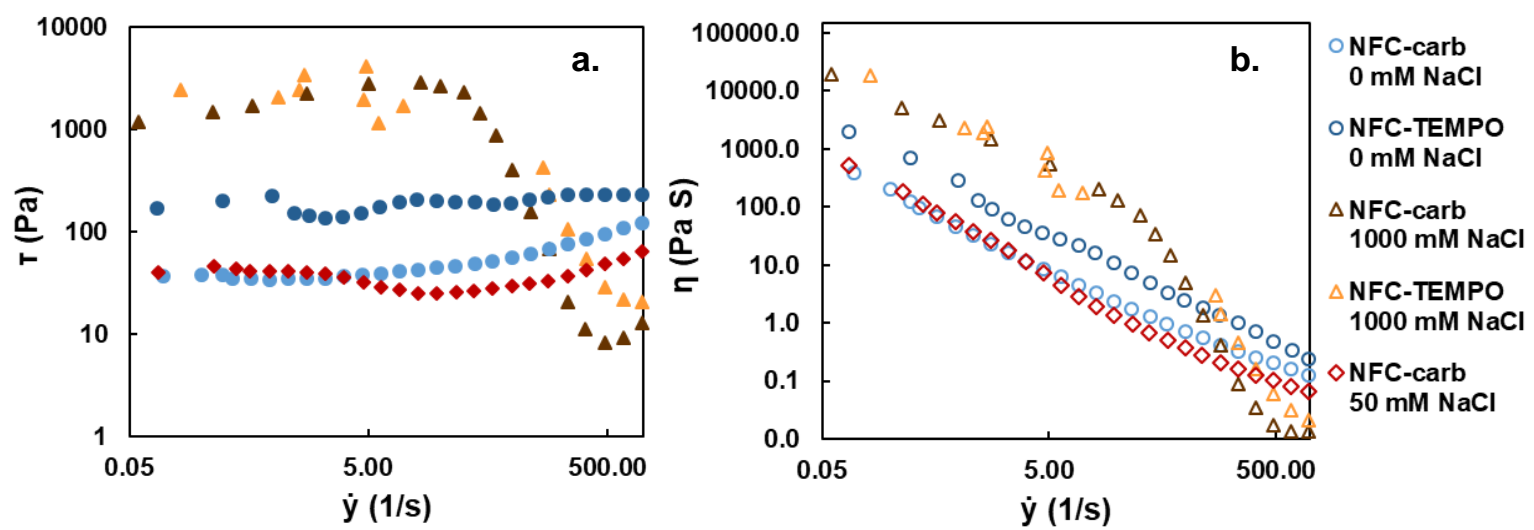

Fig. 10. Controlled rate flow curves of NFC-carb and NFC-TEMPO aqueous suspensions with and without salt addition: effect on the shear stress (a) and on the viscosity (b)

Despite the much lower degree of polymerization of the NFC-TEMPO with respect to NFC-carb (149 vs 696), the NFC-TEMPO aqueous suspension without salt addition exhibited a markedly higher shear stress for all studied shear rate ranges than the NFC-carb 
(Fig. 10). Because the NFC-TEMPO was much more nanofibrillated than the NFC-carb (Fig. 1), the results emphasized the importance of the particle size, including specific surface area, on the rheological behavior.

Comparing the effect of $\mathrm{NaCl}$ addition (Fig. 10) with ethanol or acetone additions (Fig. 3) on both shear stress and apparent viscosity, substantial differences were observed. For $\mathrm{NaCl}$ addition $(1 \mathrm{M})$, a sharp decrease in the shear stress occurred for shear rates higher than $20 \mathrm{~s}^{-1}$, suggesting a noticeable structure break, whereas the shear stress remained stable for the corresponding suspension with low ionic strength $(0 \mathrm{M} \mathrm{NaCl})$ and ethanol or acetone aqueous medium up to $40 \%$. However, for a $75 \%$ ethanol concentration (Fig. 7), the gel structure also broke.

The effect of the ionic strength on the dynamic moduli in oscillatory stress sweep assays performed with roughened surfaces is illustrated in Fig. 11 for the NFC-carb, which showed that a higher $\mathrm{NaCl}$ concentration resulted in higher dynamic moduli achieved. Moreover, as shown in Fig. 12, there was a linear increase in the storage modulus with the $\mathrm{NaCl}$ concentration, in the range $0.1 \mathrm{M}$ to $1 \mathrm{M}$. Saarikoski et al. (2012) used a mechanically disintegrated pulp (low surface charge) and also reported an increase in the storage modulus (from approximately $120 \mathrm{~Pa}$ to approximately $160 \mathrm{~Pa}$, at solid content of $1 \%$ ) with an increase in $\mathrm{NaCl}$ concentration from 0 to $100 \mathrm{mM}$; further increase in $\mathrm{NaCl}$ concentration to $1000 \mathrm{mM}$ only had a marginal effect on storage modulus, and strong microfibril aggregation was reported by the authors. Tanaka et al. (2016) also reported a linear increase in storage modulus (50 Pa to $450 \mathrm{~Pa}$ ) with $\mathrm{NaCl}$ increase from 0 to $100 \mathrm{mM}$, for an NFC with $900 \mu \mathrm{mol} /$ carboxyl content at a solid content of $0.25 \mathrm{wt} \%$. However, in this study the increase in the storage modulus was observed in the wide range of $\mathrm{NaCl}(0$ to $1000 \mathrm{mM}$ ), for both of the studied NFCs with $0.7 \mathrm{mmol} / \mathrm{g}$ and $1.9 \mathrm{mmol} / \mathrm{g}$ of carboxylate groups. It should also be emphasized that a $\mathrm{NaCl}$ concentration above $100 \mathrm{mM}$ had a marginal effect on the viscosity, but in contrast had a huge effect on the storage modulus. This linear increase of storage modulus with the $\mathrm{NaCl}$ concentration was also reported for nanocrystalline cellulose (NCC) concentrations above 7\%. These authors attributed this increase to the increase of interparticle bonds (Xu et al. 2018). The decrease of the effective particle charge (estimated by the streaming current output), observed in Fig. 9, is a prerequisite for the increase of interparticle bonds; the balance between the attractive and repulsive forces results in favor of the attractive van der Waals forces, including hydrogen bonds, when the repulsive forces diminished (Hubbe et al. 2017b).
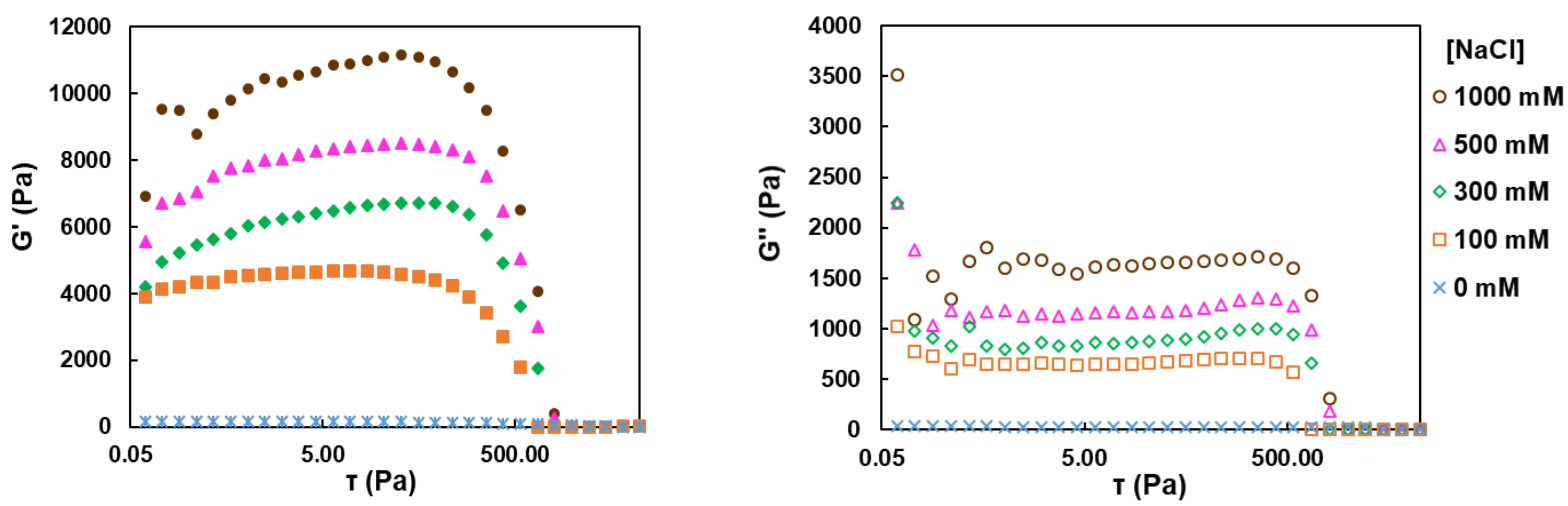

Fig. 11. Storage modulus (a) and loss modulus (b) for NFC-carb suspensions with various $\mathrm{NaCl}$ concentrations 


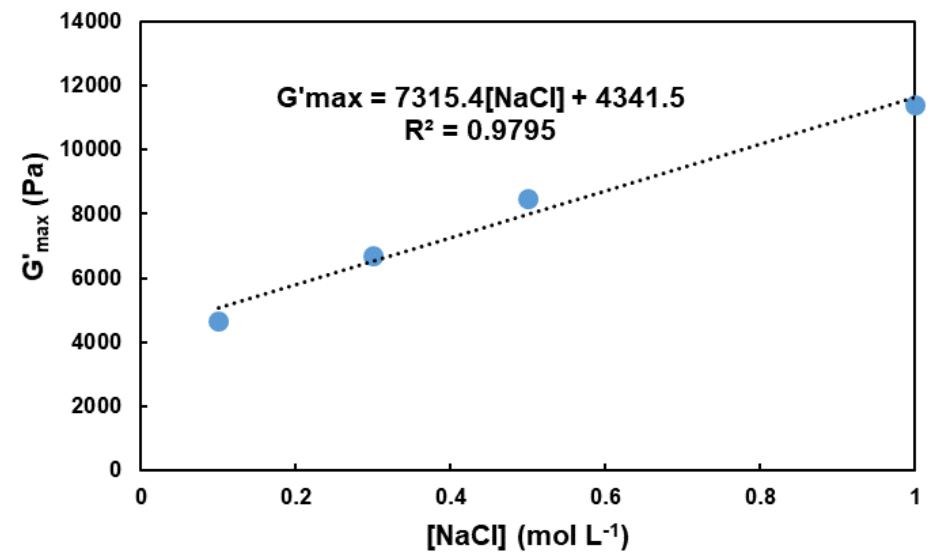

Fig. 12. Effect of $\mathrm{NaCl}$ concentration on the maximum storage modulus of NFC-carb suspensions

The comparison of $\mathrm{NaCl}$ addition with acetone addition revealed that the $\mathrm{NaCl}$ impact on storage modulus was much higher than that of acetone (Fig. 4).

The comparative behavior of NFC-carb and NFC-TEMPO materials regarding the storage and loss moduli is represented in Fig. 13, which revealed the superior performance of the NFC-TEMPO, despite both lower cellulose DP and particle size. The maximum storage modulus increased from close to $80 \mathrm{~Pa}$ to 11,000 Pa for the NFC-carb and from approximately $90 \mathrm{~Pa}$ to 28,000 Pa for NFC-TEMPO.
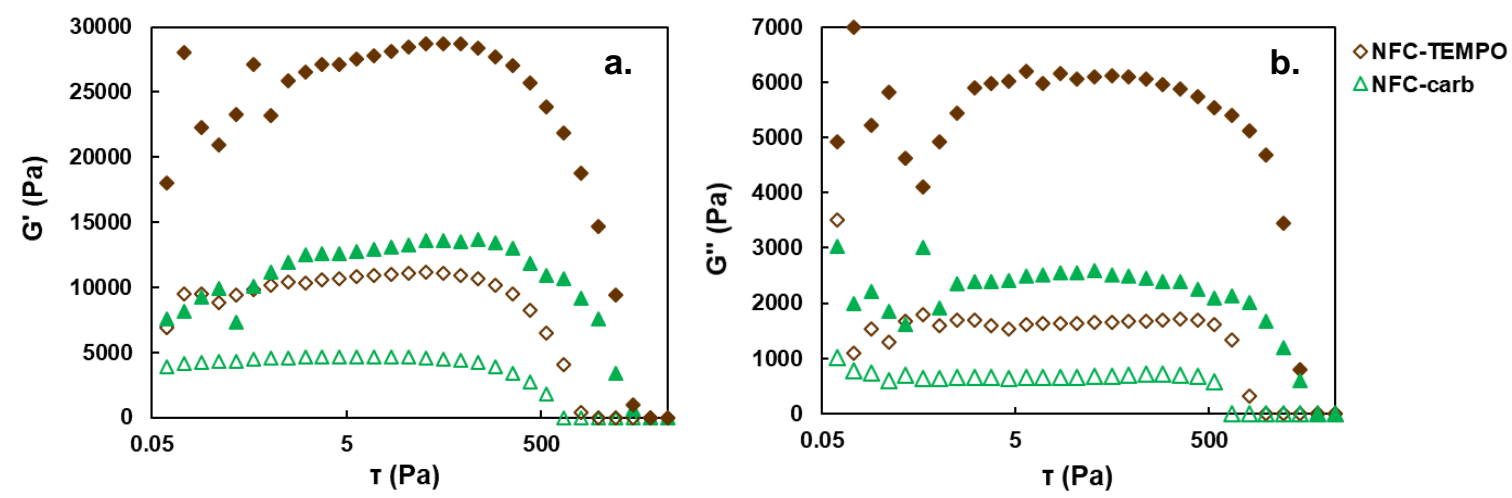

Fig. 13. Storage modulus (a) and loss modulus (b) for NFC-carb and NFC-TEMPO suspensions with $1 \mathrm{M} \mathrm{NaCl}$ (filled symbols) and $0.1 \mathrm{M} \mathrm{NaCl}$ (open symbols)

The $\tan \delta$ values for both NFCs are presented in Fig. 14, which indicated that the suspensions exhibited some elastic instability until $5 \mathrm{~Pa}$, followed by a wide plateau until $100 \mathrm{~Pa}$ (NFC-carb) and over $500 \mathrm{~Pa}$ (NFC-TEMPO), afterwards the viscous behavior began to dominate. Moreover, a comparison of the results between Figs. 14 and 5 clearly indicates that the $\mathrm{NaCl}$ addition enabled an extension in the range of elastic behavior to a higher shear stress (from $50 \mathrm{~Pa}$ to $500 \mathrm{~Pa}$ ).

Briefly, both nanofibrillation extents and ionic strengths facilitated the preparation of a cellulosic gel with a storage modulus in the range of $150 \mathrm{~Pa}$ to $28000 \mathrm{~Pa}$, at a solids content of $1.3 \mathrm{wt} \%$, which can be useful for several fields of application where the favorable gel properties are preserved.

According to Lowys et al. (2001), a small amount of $\mathrm{NaCl}$ is expected to cause a moderate electrostatic screening effect, increasing the $G$ ' to some extent. However, higher $\mathrm{NaCl}$ concentrations can result in collapse of the energy barrier and aggregation of the fibrils, which leads to a loss of homogeneous gel structure (Lowys et al. 2001; Saarikoski et al. 2012). However, in this study this did not occur in the samples until a concentration 
of $\mathrm{NaCl}$ up to $1000 \mathrm{mM}$. The gel structure only collapsed under a shear stress higher than $500 \mathrm{~Pa}$ applied at a frequency of $1.0 \mathrm{~Hz}$.
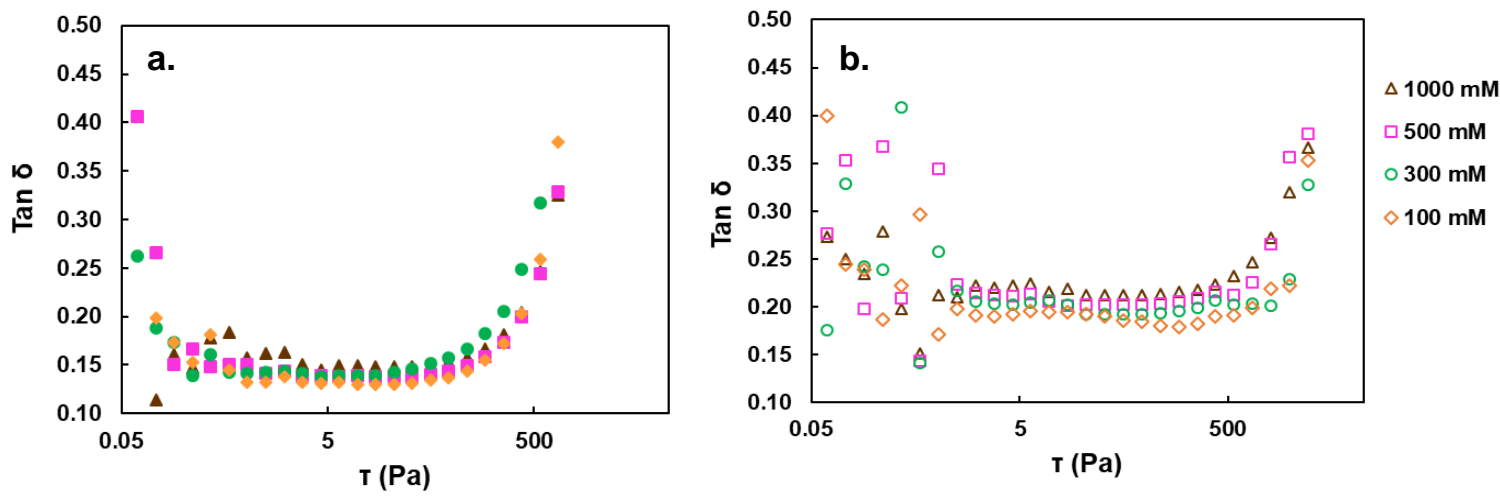

Fig. 14. Loss tangent values for NFC-carb (a) and NFC-TEMPO (b) suspensions with various $\mathrm{NaCl}$ concentrations

\section{CONCLUSIONS}

1. A small addition of either ethanol or acetone to the NFC aqueous suspension $(2.5 \%$ $(\mathrm{w} / \mathrm{w})$ ) decreased the shear stress, the viscosity, and the storage modulus from $150 \mathrm{~Pa}$ to 100 or $50 \mathrm{~Pa}$. In contrast, a concentration as high as $40 \%(\mathrm{w} / \mathrm{w})$ increased both the viscosity and storage modulus to values considerably higher than those of the aqueous suspensions, suggesting higher interfibrillar interaction, which was in accordance with the observed decrease of the absolute value of the zeta potential, from $1175 \mathrm{mV}$ to 565 $\mathrm{mV}$. The corresponding storage modulus increased from 150 to $400 \mathrm{~Pa}$.

2. An increase in the $\mathrm{NaCl}$ concentration from $50 \mathrm{mM}$ to $100 \mathrm{mM}$ led to a drastic increase in both the shear stress and viscosity. An addition of over $100 \mathrm{mM}$ of $\mathrm{NaCl}$ drastically increased the dynamic moduli, compared to the respective aqueous suspension. The maximum storage modulus linearly increased with the $\mathrm{NaCl}$ concentration (in the range of 100 to $1000 \mathrm{mM}$ ), and reached $10000 \mathrm{~Pa}$ and $28000 \mathrm{~Pa}$ for NFC-carb and NFCTEMPO, respectively, at a solid content of $1.3 \mathrm{wt} \%$. In addition, the elastic behavior of the cellulose gel was substantially extended, enduring much higher shear stress when loaded at a frequency of $1 \mathrm{~Hz}$.

3. The gel formed by NFC-TEMPO, with a higher percentage of nanofibrils and ionic charge than NFC-carb, exhibited a superior performance despite the much lower cellulose DP.

\section{ACKNOWLEDGEMENTS}

The research undertaken for this paper was performed under the UBI-Celtejo agreement. The authors would also like to thank Engineer Paulo João and Mapril (Maia, Portugal) for kindly providing the authors with the Mütek PCD-02 Particle Charge Detector. 


\section{REFERENCES CITED}

Benhamou, K., Dufresne, A., Magnin, A., Mortha, G., and Kaddami, H. (2014). "Control of size and viscoelastic properties of nanofibrillated cellulose from palm tree by varying the TEMPO-mediated oxidation time," Carbohyd. Polym. 99, 74-83. DOI: 10.1016/j.carbpol.2013.08.032

Bhushan, B., and Jung, Y. C. (2011). "Natural and biomimetic artificial surfaces for superhydrophobicity, self-cleaning, low adhesion, and drag reduction," Prog. Mater. Sci. 56(1), 1-108. DOI: 10.1016/j.pmatsci.2010.04.003

Buscall, R. (2010). "Wall slip in dispersion rheometry," J. Rheol 54(6), 1177-1183. DOI: $10.1122 / 1.3495981$

Chen, P., Yu, H., Liu, Y., Chen, W., Wang, X., and Ouyang, M. (2013). "Concentration effects on the isolation and dynamic rheological behavior of cellulose nanofibers via ultrasonic processing," Cellulose 20(1), 149-157. DOI: 10.1007/s10570-012-9829-7

Fall, A. B., Lindström, S. B., Sundman, O., Odberg, L., and Wågberg, L. (2011). "Colloidal stability of aqueous nanofibrillated cellulose dispersions," Langmuir 27(18), 11332-11338. DOI: 10.1021/la201947x

Fukuzumi, H., Tanaka, R., Saito, T., and Isogai, A. (2014). "Dispersion stability and aggregation behavior of TEMPO-oxidized cellulose nanofibrils in water as a function of salt addition," Cellulose 21(3), 1553-1559. DOI: 10.1007/s10570-014-0180-z

Haavisto, S., Koponen, A. I., and Salmela, J. (2014). "New insight into rheology and flow properties of complex fluids with Doppler optical coherence tomography," Front. Chem. 2, 1-6. DOI: 10.3389/fchem.2014.00027

Håkansson, K. M. O., Fall, A. B., Lundell, F., Yu, S., Krywka, C., Roth, S. V., Santoro, G., Kvick, M., Wittberg, L. P., Wågberg, L., et al. (2014). "Hydrodynamic alignment and assembly of nanofibrils resulting in strong cellulose filaments," Nat. Commun. 5(4018), 1-10. DOI: 10.1038/ncomms5018

Hauru, L. K. J., Hummel, M., Michud, A., and Sixta, H. (2014). "Dry jet-wet spinning of strong cellulose filaments from ionic liquid solution," Cellulose 21(6), 4471-4481.

DOI: $10.1007 / \mathrm{s} 10570-014-0414-0$

Henriksson, M., Henriksson, G., Berglunda, L. A., and Lindström, T. (2007). “An environmentally friendly method for enzyme-assisted preparation of microfibrillated cellulose (MFC) nanofibers," Eur. Polym. J. 43(8), 3434-3441. DOI: 10.1016/j.eurpolymj.2007.05.038

Hubbe, M., Ferrer, A., Tyagi, P., Yin, Y., Salas, C., Pal, L., and Rojas, O. (2017a). "Nanocellulose in thin films, coatings, and plies for packaging applications: A review," BioResources 12(1), 2143-2233.

Hubbe, M. A., Tayeb, P., Joyce, M., Tyagi, P., Kehoe, M., Dimic-Misic, K., and Pal, L. (2017b). "Rheology of nanocellulose-rich aqueous suspensions: A Review," BioResources 12(4), 9556-9661.

Iwamoto, S., Isogai, A., and Iwata, T. (2011). "Structure and mechanical properties of wet-spun fibers made from natural cellulose nanofibers," Biomacromolecules 12(3), 831-836. DOI: $10.1021 / \mathrm{bm} 101510 \mathrm{r}$

Iwamoto, S., Lee, S., and Endo, T. (2013). "Relationship between aspect ratio and suspension viscosity of wood cellulose nanofibers," Polym. J. 6(1), 73-76. DOI: 10.1038/pj.2013.64

Iotti, M., Gregersen, Ø. W., Moe, S., and Lenes, M. (2011). "Rheological studies of microfibrillar cellulose water dispersions," J. Polym. Environ. 19(1), 137-145. DOI: $10.1007 / \mathrm{s} 10924-010-0248-2$ 
Ishii, D., Saito, T., and Isogai, A. (2011). "Viscoelastic evaluation of average length of cellulose nanofibers prepared by tempo-mediated oxidation," Biomacromolecules 12(3), 548-550. DOI: $10.1021 / \mathrm{bm} 1013876$

ISO 5351 (2012). "Pulps -- Determination of limiting viscosity number in cupriethylenediamine (CED) solution," International Organization for Standardization, Geneva, Switzerland.

Janardhnan, S., and Sain, M. (2006). "Isolation of cellulose microfibrils - An enzymatic approach," BioResources 1(2), 176-188. DOI: 10.15376/biores.1.2.176-188

Jowkarderis, L., and Van de Ven, T. G. M. (2014). "Intrinsic viscosity of aqueous suspensions of cellulose nanofibrils," Cellulose 21(4), 2511-2517. DOI: 10.1007/s10570-014-0292-5

Karppinen, A., Saarinen, T., Salmela, J., Laukkanen, A., Nuopponen, M., and Seppälä, J. (2012). "Flocculation of microfibrillated cellulose in shear flow," Cellulose 19(6), 1807-1819. DOI: 10.1007/s10570-012-9766-5

Lowys, M. -P., Desbrières, J., and Rinaudo, M. (2001). "Rheological characterization of cellulosic microfibril suspensions. Role of polymeric additives," Food Hydrocolloid. 15(1), 25-32. DOI: 10.1016/S0268-005X(00)00046-1

Mendoza, L., Batchelor, W., Tabor, R., and Garnier, G. (2018). "Gelation mechanism of cellulose nanofibre gels: A colloids and interfacial perspective," J. Colloid Interf. Sci. 509, 39-46. DOI: 10.1016/j.jcis.2017.08.101

Mohtaschemi, M., Dimic-Misic, K., Puisto, A., Korhonen, M., Maloney, T., Paltakari, J., and Alava, M. J. (2014). "Rheological characterization of fibrillated cellulose suspensions via bucket vane viscometer," Cellulose 21(3), 1305-1312. DOI: 10.1007/s10570-014-0235-1

Naderi, A., Lindström, T., and Pettersson, T. (2014a). "The state of carboxymethylated nanofibrils after homogenization-aided dilution from concentrated suspensions: A rheological perspective," Cellulose 21(4), 2357-2368. DOI: 10.1007/s10570-0140329-9

Naderi, A., Lindström, T., and Sundström, J. (2014b). "Carboxymethylated nanofibrillated cellulose: Rheological studies," Cellulose 21(3), 1561-1571. DOI: 10.1007/s 10570-014-0192-8

Naderi, A., and Lindström, T. (2014). "Carboxymethylated nanofibrillated cellulose: Effect of monovalent electrolytes on the rheological properties," Cellulose 21(5), 3507-3514. DOI: 10.1007/s10570-014-0394-0

Naderi, A., and Lindström, T. (2015). "Rheological measurements on nanofibrillated cellulose systems: A science in progress," in Cellulose and Cellulose Derivatives: Synthesis, Modification and Applications, M. I. H. Mondal (ed.), Nova Science Publishers, Inc., New York, NY, USA.

Naderi, A., Koschellab, A., Heinzeb, T., Shihc, K., Niehc, M., Pfeiferb, A., Change, C., and Erlandssonf, J. (2017). "Sulfoethylated nanofibrillated cellulose: Production and properties," Carbohyd. Polym. 179, 515-523. DOI: 10.1016/j.carbpol.2017.04.026

Nechyporchuk, O., Belgacem, M. N., and Pignona, F. (2014). "Rheological properties of micro-/nanofibrillated cellulose suspensions: Wall-slip and shear banding phenomena," Carbohyd. Polym. 112, 432-439. DOI: 10.1016/j.carbpol.2014.05.092

Nechyporchuk, O., Belgacem, M. N., and Pignon, F. (2015). "Concentration effect of TEMPO-oxidized nanofibrillated cellulose aqueous suspensions on the flow instabilities and small-angle X-ray scattering structural characterization," Cellulose 22(4), 2197-2210. DOI: 10.1007/s10570-015-0640-0

Nechyporchukm, O., Belgacem, M. N., and Bras, J. (2016). "Production of cellulose nanofibrils: A review of recent advances," Ind. Crop. Prod. 93, 2-25. DOI: 10.1016/j.indcrop.2016.02.016 
Onyianta, A. J., Dorris, M., and Williams, R. L. (2018). “Aqueous morpholine pretreatment in cellulose nanofibril (CNF) production: Comparison with carboxymethylation and TEMPO oxidization pre-treatment methods," Cellulose 25(2), 1047-1064. DOI: 10.1007/s10570-017-1631-0

Ovarlez, G., Rodts, S., Chateau, X., and Coussot, P. (2009). "Phenomenology and physical origin of shear localization and shear banding in complex fluids," Rheol. Acta 48(8), 831-844. DOI: 10.1007/s00397-008-0344-6

Pääkkö, M., Ankerfors, M., Kosonen, H., Nykänen, A., Ahola, S., Österberg, M., Ruokolainen, J., Laine, J., Larsson, P. T., Ikkala, O., et al. (2007). "Enzymatic hydrolysis combined with mechanical shearing and high-pressure homogenization for nanoscale cellulose fibrils and strong gels," Biomacromolecules 8(6), 1934-1941. DOI: $10.1021 / \mathrm{bm} 061215 \mathrm{p}$

Saarikoski, E., Saarinen, T., Salmela, J., and Seppälä, J. (2012). "Flocculated flow of microfibrillated cellulose water suspensions: An imaging approach for characterization of rheological behaviour," Cellulose 19(3), 647-659. DOI: 10.1007/s 10570-012-9661-0

Saarinen, T., Lille, M., and Seppälä, J. (2009). "Technical aspects on rheological characterization of microfibrillar cellulose water suspensions," Annu. Trans. Nord. Rheol. Soc. 17, 121-130.

Saito, T., Kimura, S., Nishiyama, Y., and Isogai, A. (2007). "Cellulose nanofibers prepared by tempo-mediated oxidation of native cellulose," Biomacromolecules 8(8), 2485-2491. DOI: $10.1021 / \mathrm{bm} 0703970$

SCAN-CM 65:02 (2002). “Total acidic group content," Scandinavian Pulp, Paper and Board Testing Committee, Stockholm, Sweden.

Shinoda, R., Saito, T., Okita, Y., and Isogai, A. (2012). "Relationship between length and degree of polymerization of tempo-oxidized cellulose nanofibrils,"

Biomacromolecules 13(3), 842-849. DOI: 10.1021/bm2017542

Sluiter, A., Hames, B., Ruiz, R., Scarlata, C., Sluiter, J., Templeton, D., and Crocker, D. (2012). Determination of Structural Carbohydrates and Lignin in Biomass (NREL/TP-510-42618), National Renewable Energy Laboratory Golden, CO, USA.

Smith, D. K., Bampton, R. F., and Alexander, W. J. (1963). "Use of new solvents for evaluating chemical cellulose for the viscose process," Ind. Eng. Chem. Proc. DD. 2(1), 57-62. DOI: 10.1021/i260005a012

Tanaka, R., Saito, T., Hänninen, T., Ono, Y., Hakalahti, M., Tammelin, T., and Isogai, A. (2016). "Viscoelastic properties of core-shell-structured, hemicellulose-rich nanofibrillated cellulose in dispersion and wet-film states," Biomacromolecules 17(6), 2104-2111. DOI: 10.1021/acs.biomac.6b00316

Tanaka, R., Saito, T., Hondo, H., and Isogai, A. (2015). "Influence of flexibility and dimensions of nanocelluloses on the flow properties of their aqueous dispersions," Biomacromolecules 16(7), 2127-2131. DOI: 10.1021/acs.biomac.5b00539

Tanaka, R., Saito, T., Ishii, D., and Isogai, A. (2014). "Determination of nanocellulose fibril length by shear viscosity measurement," Cellulose 21(3), 1581-1589. DOI: 10.1007/s10570-014-0196-4

Wagberg, L., Decher, G., Norgren, M., Lindstrom, T., Ankerfors, M., and Axnas, K. (2008). "The build-up of polyelectrolyte multilayers of microfibrillated cellulose and cationic polyelectrolytes," Langmuir 24(3), 784-795. DOI: 10.1021/la702481v

Walther, A., Timonen, J. V., Diez, I., Laukkanen, A., and Ikkala, O. (2011). "Multifunctional high-performance biofibers based on wet-extrusion of renewable native cellulose nanofibrils," Adv. Mater. 23(26), 2924-2928. DOI:

10.1002/adma.201100580 
Xu, Y., Atrens, A. D., and Stokes, J. R. (2018). “ 'Liquid, gel and soft glass' phase transitions and rheology of nanocrystalline cellulose suspensions as a function of concentration and salinity," Soft Matter 14, 1953-1963. DOI: 10.1039/C7SM02470C

Article submitted: May 2, 2019; Peer review completed: July 13, 2019; Revised version received and accepted: July 30, 2019; Published: August 5, 2019.

DOI: $10.15376 /$ biores.14.4.7636-7654 